\title{
Capillary Electrophoresis
}

National Cancer Institute

\section{Source}

National Cancer Institute. Capillary Electrophoresis. NCI Thesaurus. Code C17637.

An electrophoresis procedure, in which a sample is introduced into a capillary tube and the components are separated by the application of high voltage. Due to the large surface to volume ratio, cooling is more efficient, allowing use of higher voltages. As a result, separation occurs more quickly and sensitivity is increased. The technique allows for separation of proteins, nucleic acids, and carbohydrates. 